\title{
On certain functional approaches to word order
}

This paper* does not address word order phenomena directly; its main topic concerns certain approaches to word order; thus this topic is somewhat limited. What $I$ will be doing here is to identify a certain approach to word order, and to criticize it. The authors to be considered have at least this aspect in common - besides unmistakable differences - that they (at least partiy) try to describe word order phenomena in terms of an assumed function of word order rather than in terms of formal constraints. I will not discuss all kinds of approaches that might be called "functional" in this sense, but especially some which may be said to present linguistic descriptions in the form of descriptions of the production of utterances. It is this last aspect that constitutes the actual topic of this paper: I will argue that it is a major source of a demonstrable lack of coherence in the descriptions to be considered. 1

Firstly - and most extensively - I will consider the ANS (short for Algemene Nederlandse Spraakkunst: "General Grammar of Dutch"), the recent comprehensive reference grammar of Dutch and the first grammar of Dutch, to my knowledge, to attempt a comprehensive account of word order phenomena. At the beginning of a long chapter on word order in the sentence (Chapter 22, pp. 909-1047), the 'theory' of the ANs is expounded; consider the following passages (the translation is mine; italics and capital letters from the original, boldface type mine; - AV):

The most prominent phenomenon in the use of the language as far as word order is concerned is that word order is to an important extent 1inked up with the articulation of information (cf. ANS 1984: 911).

The relation between word order and the articulation of information in a sentence can now be expressed as follows: in a large number of sentences, the elements with the lesser informational value are placed before the elements with a higher informational value. We will call sentences in which this is the case: UNMARKED, [..] Therefore we will call this phenomenon the LEFT-TO-RIGHT PRINCIPLE (cf. ANS 1984: 913).

The first remark I want to make relates to the parts of this text that I indicated in boldface type. In view of these formulations, the ANs does not express a theory of a general function of word order. For word order is linked up to the articulation of information only "to an important extent", so not really generally; elements with higher informational value come before others often, so not always; thus it cannot be the the general function of word order to indicate that elements "in front" are informationally less important.

It is not a very good start, I think, if a relation that is not generally valid is called "the most prominent phenomenon [...] as far as word order is concerned"; this at least introduces a certain risk if the function of word order is to be explained: from the very beginning on, the content of the interpretive side of word order is not really clear. Additionally, there is in fact no clarity about the relevant phenomena as well; the question is: under what conditions are we to say that a difference between two sentences boils down to a difference in word order? In the ANs, the answer is implied 
in the following passage, meant to illustrate the "left-to-right principle":

Compare, for example, the sentences (5) and (6), which, in a different order, contain precisely the same elements. The element that bears the sentence accent is in italics.

(5) Morgen komt Erwin

Tomorrow comes Erwin

"Tomorrow Erwin is coming"

(6) Erwin komt morgen

Erwin comes tomorrow

"Erwin is coming tomorrow"

(cf. ANS 1984: 913/4).

It is clearly suggested that the only difference between (5) and (6) is a difference of order, and that a (possible) interpretive difference between these sentences may be attributed completely to this difference of order. Apparently, the idea is that both sentences have the same accentuation, with the sentence accent at the end of the sentence. But this idea is open to criticism, to say the least: it is different elements that bear the accent in (5) and in (6). Taking this into consideration, there are (at least) two differences between (5) and (6), a difference of order and a difference of accentuation; in this perspective it is not clear a priori whether interpretive differences between the two sentences should be attributed to order, to accentuation, or possibly to this specific combination of the two. What is attributed to order and what to accentuation is, in that case, entirely dependent on analysis; for the ANS, this dependency on analysis does not exist, for the "observation" is simply that there is no more than one factor involved (word order). On the view to be expounded here, on the other hand, other "observations" will be relevant to an analysis of the role of word order as well as accentuation; thus it seems better to say that word order indeed constitutes the only difference between (5) and (6)', since the same meaningful elements are accented in both sentences, and the same is valid for (5), and (6).2

(5)

\section{Morgen komt Erwin}

Tomorrow comes Erwin

"Tomorrow Erwin is coming"

(6) Erwin komt morgen

Erwin comes tomorrow

"Erwin is coming tomorrow"
(5)' Morgen komt Erwin Tomorrow comes Erwin "Tomorrow Erwin is coming" Erwin komt morgen Erwin comes tomorrow "Erwin is coming tomorrow"

The reason for the authors of the ANS not to take this route is to be found in the fact that they restrict the validity of their 'theory' to what are called "unmarked sentences", specifically sentences without a contrastive accent. What is to be understood by that is not made very clear, though, and this does not contribute much to the coherence of the description. In the following passage about contrastive accent $I$ have marked certain parts in boldface type.

The formulation of the left-to-right principle given above is valid [...] only for sentences that we called unmarked. However, the [...] informational value of the elements does not always find expression only through their position in the sentence. All kinds of accentuation phenomena too, may play a role here. What is especially important is CONTRASTIVE ACCENT. By means of such an accent (and/or by means of placing something at the beginning or at the end), the speaker may indicate the contrast with what 
is, in the context, before or after the accentuated element (cf. ANS 1984: 915).

In short: it is not very clear what is related to what, exactly. But more important for the purpose of this paper is the fact that this description makes no connection whatsoever between the role of word order in "unmarked" and "marked" cases. It seems as though word order has no function in marked cases, since the function it might have had (indicating informational value) has been taken over by something else. That is rather odd in itself; moreover, it is not clear at all why contrasting something with something else in the context should allow elements with a higher informational value to occur at the beginning of sentences: What is the conceptual relation between the two? What connects contrast to word order?

What could be the source of the ANS not asking such questions? I would suggest that at least one of the reasons is the view that the concept of informational value is somehow given in advance, prior to a linguistic expression, and just 'finds expression' in one linguistic form or another. The shape of the description is that there is a certain 'content' (in this case: informational value) that takes shape in some linguistic utterance, sometimes in the form of accentuation, sometimes in the form of word order. Now what is the 'locus' of this content, if it is not the linguistic expression? It is clear from the passage cited above that the answer given by the ANS is: the speaker. What I want to suggest now is that it is not at all strange, but rather to be expected that a concept established independently of an analysis of word order (or any other linguistic phenomenon, for that matter) will turn out not to be related to word order generally. This would lead to a relatively chaotic description, in which it is not very clear how different aspects of the description (both of form and of content) are conceptually related.

It should be noted that locating the content of an expression in the speaker is a sufficient, but not a necessary condition for a description in terms of concepts established independently of an analysis of order. It is clear, for example, that the shape of the description in the following passage from Blom \& Daalder (1977) is not from "speaker meaning" or "speaker intention" to Iinguistic expression, but there is nevertheless a certain conceptual parallel to the description by the ANS. ${ }^{3}$

As for the impression of contrast [..], we could describe its contents as the feeling that this part [i.e., known information - AV] is or has been introduced verbally, into the context (cf. Blom \& Daalder 1977: 87). One could attribute the [...] impression of contrast to an interpretive (perceptual) tendency towards 'positioning' the focus towards the end of the sentence as far as possible, thus to expect the order presupposition-focus. A sentence accent at the beginning of a sentence in Dutch would then easily lead either to the focus ranging over the entire S[entence]-structure, or to the unexpected, contrastive 'positioning' focus-presupposition (cf. Blom \& Daalder 1977: 88).

In this view, some relation does exist between contrast and word order, but it is still true that the nature of this relation is such that one kind of sentences is seen as a deviation from some norm: the expected position of the news is at the end of the sentence. Furthermore, it is also true that there is not really a conceptual link between the content of the notion of contrastiveness and the function of word order. The content of the first notion is the idea that old information has been introduced verbally, and does not just refer to common information without speaker or hearer having 
expressed it; now why would a violation of the expectation that the news comes at the end lead to the hearer interpreting the old information as a kind of 'echo', a repetition of something that has already been said? Again: what is the conceptual relation between these two notions? Note, finally. that this description does not generalize over the function of word order in contrastive and non-contrastive sentences either.

Although the quoted passage is not formulated in terms of "speaker meaning", 4 it has nevertheless much in common with the description presented in the ANS. Note, specifically, that in fact the assumed tendency - in this case, an interpretive rather than 'producing' tendency - is logically prior to the interpretation of actual expressions. Consequently, the content of expressions is described in terms of a notion that is completely independent of word order, conceptual1y. The tendency mentioned is not explained in terms of some function of order, but it is the other way around: the order of informational elements can be said to be described as either 'in accordance with', 'derivable from' the tendency or not (if not, it is contrastive, otherwise it is not).

Returning now to the ANS, the next thing to be noted is that it describes word order not only in terms of 'information structure', but also in terms of something else: grammatical functions. However, the relevance of these notions to word order is not stated as explicitly as the relevance of information structure. The section on the so-called middle part of Dutch sentences first divides this into three "main groups", in accoxdance with the left-to-right principle: subjects and objects with lesser informational value (I) precede adverbial phrases (II), which in turn precede subjects and objects with greater informational value (III) (cf. ANS 1984: 976). But quite soon after the introduction of this "ordering tendency", the reader gradually loses his way in a continuously growing number of distinctions. Within each of the main groups I and III (together covering alI positions for subject and objects), 7 different positions are distinguished, i.e. 7 types of 'slots' for different types of elements, in a specified order; the following schema presents an overview.

Schema I:

3 main groups:

I

informationally unimportant subjects and objects
II

adverbial
phrases
III

informational1y important subjects and objects

Both within I and III: 7 distinct positions for 'sub-groups', in this order:

1

2

3

4 5

personal| er ("there")|nominal |reduced |reduced Inon+ demon-1 as 'dummy' strative| subject subject pronouns | trindef.
pronominal |pro|subjects|nouns
Ist and 2nd ps. lobject Ipronouns reduced |+ indef. prolobject /nominal, and |pronouns/nominal lobjects

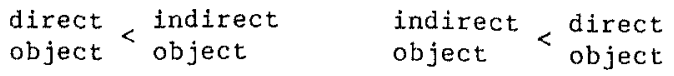

As indicated, three of these sub-rules are qualified with other sub-rules: in groups 4,5 and 7 rules are stated for the relative order of direct and indirect objects. But even apart from this complication there are at least 
14 'slots', maximally 3 of which can be 'filled' in one sentence at the same time. Furthermore, the ANS also appears to adhere to another theory about the function of word order than the one that is explicitly expounded (the left-to-right principle): there is also a more implicit theory according to which there is a connection between the position of (pro-)nominal elements and their grammatical roles: schema I embodies the assumption that subjects of all different kinds precede objects (the first 3 positions are for subjects, the final 4 are for objects), and it explicitly states that order is connected to the difference between direct and indirect objects. This description is already far too complex to be surveyable; the reader has to 'recalculate' the possibilities all the time. But then this highly complex set of rules stili meets with several 'exceptions', most of which are mentioned in the ANS itself:

Exceptions to schema I (with indication of the 'violation'): 5

(16) Hoeveel zou me dat kosten?

IO $-\mathrm{SU}$

How-much would me that cost

"How much would that cost me?"

(81b) Heeft je dat die jongen dan toch gegeven?

Has you that that boy then still given

"Did that boy then give it to you after aIl?"

p.981 Toch heeft hem dat geen voordeel opgeleverd

Yet has him that no profit yielded

"Yet he did not gain profit from that"

p.981 Steeds weer leek hem zo'n opgave onuitvoerbaar

IO-SU

Ever again seemed him such-a task unworkable

"Every time he thought such a task unworkable again"

(40) Nooit heeft hem dat geinteresseerd

$\mathrm{DO}-\mathrm{SU}$

Never has him that interested

"Never has he had interest in that"

(71)a Blijkbaar was de leraar het wachten toch niet onwelgevallig IO-SU Apparently was the teacher the waiting yet not unpleasant

"Apparently the teacher yet found the waiting not unpleasant"

(74) Daarom werd de burgemeester een schilderij aangeboden

Therefore was the mayor a painting offered

"Therefore the mayor was offered a painting"

IO-SU

Nieuwborg (1968: 116-118, 217) gives some typical examples of sentences with a pronominal, "human" direct object and an "abstract", "psychological" subject, occurring in that order (the reverse order in fact is "marked"):

(a) Toen besprong har eensklaps een radeloze angst

DO-SU

Then jumped-upon her. suddenly a desperate fear

"Then she was suddenly seized with a desperate fear"

And in Verhagen (1986: chapter 6), still more examples are presented:

(b) (Ik denk dat) ik dit boek niemand zou willen aanbevelen

DO - IO

(I think that) I this book nobody would want recommend

"(I think that) I would not recommend this book to anyone"

(c) Nu is mijalles duidelijk

IO-SU

Now is me everything clear

"Now everything is clear to me"

(d) Gisteren is ons een ramp overkomen

Yesterday is us a disaster befallen

"Yesterday we met with a disaster"

IO-SU 
(e) Gisteren heeft ons een ramp getroffen

$\mathrm{DO}-\mathrm{SU}$

Yesterday has us a disaster hit

"Yesterday a disaster hit us"

So this implicit relation between word order and roles also looks more like a tendency than a general rule. But in this case the deviations' from the norm do not, unlike 'violations' of the left-to-right principle, give rise to special interpretive effects, like contrastiveness. However, it is not at al1 surprising that readers get lost in this labyrinth.

Summarizing: despite its merits as a first attempt, the description of word order in the ANS clearly shows a lack of coherence. This incoherence is especially manifest in the fact that there are both an explicit and an implicit theory about the function of word order, without an inherent connection between these two theories, in the fact that contrastiveness is conceived as a deviation from a norm (the unmarked case), and in the fact related to the two other points - that there is no idea about a truly general function of word order, an idea that would allow for a generalization over the role of order both in marked and in unmarked sentences.

One important source of this confusion seems to be that the description in the ANS takes the shape of an instruction for the production of sentences. It has the form of a series of answers to the question: "How does a speaker make a string out of the elements of a sentence?" The answers have the shape of a number of instructions to line up such elements. Now the very nature of this question and the answers to it implies that the description is present ed in terms of $1 \mathrm{ining} u p$ elements which are characterized independently of word order - these characterizations may thus be of ary kind. It is not necessary that they are conceptually related, and, even more confusing, it is not necessary that they are conceptually related to word order; in fact it should be regarded a coincidence when independent characterizations of linguistic elements appear to be linked up with order. In this perspective it is completely understandable that one encounters descriptions of the following type: "Informationally important elements should in general be placed towards the end of the sentence, but if an element is contrastive, this is not necessary", or: "An object should in general follow a subject, but this is not always necessary; in certain circumstances an object may even better precede a subject, though this is not obligatory". The chapter on word order of the ANS abounds in such formulations. And it may be considered significant that the reader is not informed whether there is an interpretive difference - and if so, of what kind - between one order of certain elements and another. In view of such examples as presented above, the first 'conclusion' should be, of course, that the function of word order does not involve differentiation of the traditionally distinguished grammatical roles, since these roles may in principle occur in any order. ${ }^{6}$ The question that should be posed is not in what order independently characterized elements may and may not occur, but rather what effect word order has when elements, of whatever kind, are combined into a sentence.

Thus, my thesis is that at least one important cause of the lack of coherence in the description lies in its 'generating' character; ${ }^{7}$ this just implies that elements that have been characterized on other grounds than a consideration of word order are being 'placed' relative to each other; and it is very likely that the distinctions used - for example the one between subject and object - are not at all relevant to the role of word order. It should hardly be expected otherwise, in fact. This easily gives rise to the impression that an element of type $x$ may sometimes occur in one place, and sometimes in another - whether as an 'exception' or as the 'rule', and that 
word order ("therefore") is a highly complicated phenomenon, to be characterized as the result of a number of tendencies, possibly conflicting, and therefore never without exceptions.

Authors of reference grammars generally do not create new descriptive traditions; they rather follow established patterns. It is to be expected, therefore, that the linguistic literature contains similar approaches to word order, which can be shown to contain similar problems. I already mentioned Blom \& Daalder (1977) (and Verhagen (1979)): though they use an 'interpretive' strategy rather than a 'generating' one, the content of the analysis, especially of the source of contrastiveness, is parallel to that of the ANS, in that word order is described in terms of some independently established concept. But I now want to concentrate on some 'generating' proposals, in order to show that these consistently seem to exhibit this feature. A clear example of such a description is to be found in Garcia (1979). The main point of the general part of her analysis of word order can be summed up as follows: (cf. García 1979: 33)

\section{Schema II:}

It is at the beginning of 'communications'/'utterances' that the addressee knows least, that is, is most ignorant.

Therefore: at the beginning the hearer is forced to depend completely on the speaker's words for his understanding of the message;

Therefore: it is at the beginning that the hearer's attention for the speaker's words will be maximal;

Therefore if the speaker wants to communicate effectively, he will take this fact (hearer's attention maximal at the beginning) into account;

Therefore: the speaker will place at the beginning of 'communications' 1 'utterances' those elements that he wishes (for any of a variety of reasons) to bring to the hearer's attention.

Garcia's purpose is to explain why speakers line up their words as they do. To that end, a chain of reasoning is created that, though departing from an interpretive purpose of the hearer, results in the postulation of a speaker's strategy. As a whole, this argument gives a rather 'overworked' impression of both hearer's and speaker's psychology. But it is a different aspect that makes this analysis similar to the one given in the ANS. This explanation of word-order phenomena is a causal one: the speaker's strategy causes the words to appear in this order and no other. Thus the phenomena are indeed analysed as 'generated' by the strategy. In order to describe concrete cases, however, more has to be said, and to that end a distinction is made between four types of elements worthy of attention:

Types of elements worthy of attention:

1. "item which is familiar from the context";

2. "item which is important, that is, on which the speaker wishes to concentrate the hearer's attention";

3. "item which is indispensable for the understanding of other material";

4. "item which provides background information for the event".

(cf. Garcia 1979: 34; italics added)

It is at this point that problems of coherence arise. For it is not at all clear that something's being worthy of attention is manifested in precisely these ways; and it is not clear either, what the differences between some of these types are (for example, between 1 and 4 , or 3 and 4 ). Moreover, the analysis suggests (and must suggest) that it can be determined independently 
of word order whether something is familiar, important or background information; but in that perspective it is impossible to explain why so-called 'new' information should not be placed at the beginning: is it not especially worthy of attention? The reverse more or less holds in the case of familiar information: Why would that be especially worthy of attention, more than unfamiliar information in the same sentence?

In this case too, it seems, the lack of coherence is related to the general 'generating' character of the description: this necessitates a characterization of the relevant contents of elements independentiy of order, and thus it is to be expected that the notions used are not conceptually related, neither to each other nor to word order. ${ }^{8}$ Note, furthermore, that this analysis does not contain an idea about a conceptual relation between contrast and word order; it is true that contrastiveness is not as such part of Garcia's topic, but on the other hand it is not clear either how such a relation could be incorporated into the analysis.

Finally, the proposals on the function of word order in Kirsner (1979) offer a possibility of showing that the approach of the ANS and Garcia's are in fact quite similar. Kirsner's own analysis is formulated completely in terms of a strategy to have familiar information precede new, and the reverse order is accordingly characterized as a deviation; so far this looks very much Iike what we saw in the ANS (and, in fact, in Blom \& Daalder (1977) and Verhagen (1979)). But at the beginning of his analysis, Kirsner demonstrates in a very clear manner that this strategy precisely fits Garcia's general hypothesis: by presenting familiar information first, one supplies the necessary background information, thus reducing the effect of the hearer's ignorance (Kirsner 1979: 99/100).9 But the terms which Kirsner employs in his actual description of word order only involve the strategy of nfamiliar items first"; thus for his descriptive purposes the connection with Garcia's general theory is in fact superfluous. So again there is a certain lack of coherence; what is especially clear in this case, however, is that the 'generating' nature of the description prohibits a generalization over the role of order in different sentences: that role simply cannot be the same in cases where the speaker does not follow the "familiar items first" strategy, and this idea of a strategy neither provides insight into the connection between the role of word order and the contents of the notion of contrastiveness. 10 So we are back at where we started from: the idea of a 'strategy' or 'tendency' as somehow essential to our understanding of word order makes it impossible to even pose the question of a general function of word order.

In conclusion: there is a rather widespread practice in functional approaches to word order, to describe this in terms of concepts that are established independently of an analysis of order. On the one hand, this is a source of the lack of coherence to be found in a number of such descriptions. On the other hand, it is itself often a consequence (though not in all cases) of a 'generating' mode of description, the reason being that this is a sufficient (though not necessary) condition for presenting the descriptions in terms of distinctions that are necessarily independent of the analysis of word order. and thus do not have to be relevant to that analysis at all.

Notes

* This paper was written within the framework of the Free University Research Programme "Functional Language Research: Grammar and Pragmatics" (LETT 83/9), which is financed by the Dutch Ministry of Education. 
1. Thus, reasons will be given for an approach alternative to those to be considered in the text, without this alternative itself being presented; see Verhagen (1986, esp. chapter 5) for an elaboration of such an alternative.

2. The reasons for this criticism and for adopting the alternative view are discussed extensively in Keijsper (1985). It should be noted that the ANS does mention the sentences (5)' and (6)'; however, it does so a few pages later (916), and the point of the examples there is only that such sentences exhibit a "deviant" order, i.e., do not conform to the theory of the left-to-right-principle, and are therefore called "marked". See the comments in the text on the passage on contrastiveness from p. 915.

3. The comments to be made in the text also apply to Verhagen (1979; e.g., p. 388), at least for those parts that are based on the analysis by Blom \& Daalder.

4. Note however, that some other passages relating to the same phenomena are formulated in terms of "positioning" focus and presupposition relative to each other, which is more reminiscent of a speaker's strategy (cf. Blom \& Daalder (1977, p. 87): "It is [...] less natural to let the focus precede the presupposition", "a presupposition which is present only on the basis of [...] common knowledge is never positioned after the focus [...]"; italics added).

5. The numbers of the examples are from the ANS; unnumbered examples are preceded by the number of the page on which they occur. The judgements are from the ANS; I do not agree completely with all of them.

6. This leaves open the question if there is any aspect of linguistic form that does involve differentiation of such roles, or if these are simply 'phantoms'.

7. In this perspective, the criticism of the ANS by smits (1986) - to the effect that the ANS is wrong in describing word order in terms of semantic and pragmatic rather than formal notions - can be said to be superficial, at best.

8. Garcia's description differs positively from the one in the ANS in at least one important respect: she explicitly attempts to generalize over the role of word order in marked and unmarked sentences. But the success of the attempt may be doubted: according to Garcia, placing the Nominative at the beginning of the sentence is "natural", because of the meaning of the Nominative (FoCUS, i.e. "most worthy of speaker's interest"), but placing a $\mathrm{NP}$ with another case in front is done for special purposes (cf. Garcia 1979: 35).

9. Note that this argument is developed independently of an intermediate step of "noteworthiness", which reinforces the conclusion that there is in fact no inherent connection between the notions involved.

10. In terms of the analysis in Verhagen (1986), this connection can be formulated globally as follows. The function of word order is that the idea evoked by an element $X$, preceding an element $Y$, is understood as perceivable independently of the idea evoked by $Y$. The function of sentence accent is that the accented element is understood as being introduced into the discourse (as being 'news'). If the element containing sentence accent (X) precedes an unaccented element, then the news is presented as perceivable independently of the background information; the latter thus does not 
constitute necessary background information, and is therefore easily felt to repeat some background information (cf. Verhagen 1986, esp. 165-167).

References

ANS

1984 Algemene nederlandse spraakkunst. Edited by G. Geerts, W. Haeseryn, J. de Rooij, M.C. van den Toorn. Groningen/Leuven: WoltersNoordhoff.

Blom, A. \& S. Daalder

1977 Syntaktische theorie en taalbeschrijuing. Muiderberg: Coutinho.

García, E.C.

1979 'Discourse without syntax'. In: T. Givón (ed.), Syntax and semantics 12: discourse and syntax. New York: Academic Press, $1979,23-49$.

Keijsper, C.E.

1985 Information structure. With examples form Russian, English and Dutch. Amsterdam: Rodopi.

Kirsner, R.S.

1979 The problem of presentative sentences in modern Dutch. Amsterdam: North-Holland Publishing Company.

Nieuwborg, E.

1968 De distributie van het onderwerp en het 1ijdend voorwerp in het huidige geschreven Nederlands in zijn A.B.-vorm. Antwerpen: plantyn.

Smits, R.

1986 'De gemiste kansen van de ANS'. De nieuwe taalgids 79, 388-406.

Verhagen, A.

1979 'Fokusbepalingen en grammatikale theorie'. Spektator 8, 372-402.

1986 Linguistic theory and the function of word order in Dutch. Dordrecht: Foris. 